\title{
Study on Indonesian Overall Thermal Transfer Value (OTTV) Standard
}

\author{
Iman Paryudi ${ }^{a, b, *}$, Stefan Fenz ${ }^{a}$, A Min Tjoa ${ }^{a}$ \\ ${ }^{a}$ Vienna University of Technology, Vienna, Austria, 1040 \\ ${ }^{b}$ Pancasila University, Jakarta, Indonesia, 12640
}

\begin{abstract}
Currently buildings in the world become the biggest energy consumers. Energy efficient buildings must be built to reduce energy use by buildings. Building standards is needed to achieve this goal. One of the building standards is based on Overall Thermal Transfer Value (OTTV). The OTTV is a value indicating the average rate of heat transfer into a building through the building envelope. The first country in Asia to adopt the standard is Singapore. It is then followed by other countries in South Asia region including Indonesia. The current Indonesian standard on OTTV is Envelope Energy Conservation in Buildings, SNI 6389: 2011. Parametric analysis on OTTV formula based on Indonesian standard shows that the parameter having the biggest and the smallest impact on OTTV value is window-towall ratio and wall absorptance, respectively. The experiment also reveals that different building orientations will cause only small change in OTTV value.
\end{abstract}

Keywords: OTTV, Energy Efficient Building, Parametric Analysis, Energy Conservation

\section{Introduction}

Buildings are some of the biggest energy consumers in the world, accounting for one quarter to one-third of all energy use and a similar amount of greenhouse gas emissions [1]. In the US, buildings are responsible for nearly $48 \%$ of total energy consumption [2]. In Europe, they account for $40 \%$ of energy consumption [3]. Meanwhile in the UAE, $70 \%$ of primary domestic energy is committed to buildings [4]. And in Indonesia, buildings use $40.8 \%$ of the whole electricity consumption [5].

Knowing the facts above, action must be taken to reduce the electricity use by buildings. One of the most effective ways is to issue standard that controls the energy use by buildings. A developer which will develop a building must calculate the energy use by the building. The building is not allowed to be erected if the calculated energy use is larger than the standard maximum value.

The Government of Indonesia has implemented several energy efficient standards. One of the standards is Envelope Energy Conservation in Building, SNI 6389:2011. This standard is based on Overall Thermal Transfer Value (OTTV). In this standard, the allowable OTTV value in Indonesia is $35 \mathrm{~W} / \mathrm{m}^{2}$ [6]. This paper will describe the standard and explain an application developed based on it. The rest of the paper is structured as follows: section 2 explains the OTTV, followed by Indonesian OTTV standard in section 3 . Section 4 describes the application developed based on the Indonesian OTTV standard. Section 5 presents parametric analysis on the OTTV formula to know the effect of each parameter on the OTTV value and the result is discussed in section 6. Section 7 concludes the paper.

\section{Overall Thermal Transfer Value (OTTV)}

The American Society of Heating, Refrigerating and Air conditioning Engineers (ASHRAE) had originated the Overall Thermal Transfer Value (OTTV) as a thermal performance index for the envelope of air-conditioned buildings in 1975 [7]. This was called ASHRAE Standard 90-75. This standard was then revised as ASHRAE Standard 90A-1980 [8].

The concept of OTTV is based on the assumption that the envelope of a building is completely enclosed [9]. Therefore, OTTV is a value that indicates the average rate of heat transfer into a building through the building envelope. The term building envelope refers to the outermost layer of a building [10]. It is the interface between the interior of the building and the outdoor environment, including the foundation, roof, walls, doors and windows. By acting as a thermal barrier, the building envelope plays an important role in regulating interior temperatures and helps determine the amount of energy

* Corresponding author. Tel.: +436505106135

E-mail: paryudi@ifs.tuwien.ac.at

(c) 2013 International Association for Sharing Knowledge and Sustainability

DOI: $10.5383 /$ ijtee.06.02.001 
required to maintain thermal comfort. Minimizing heat transfer through the building envelope is crucial for reducing the need for space heating and cooling. In hot climate, the building envelope can reduce the amount of energy required for cooling. In cold climate, the building envelope can reduce the amount of energy required for heating [11]. Heat gain or loss between exterior surrounding and a space separated by a building envelope takes the form of conduction transfer through the opaque part of the envelope, radiation, and conduction transfer through the transparent fenestration and exchange of air through ventilation and air leakage [12]. In the OTTV formulation, factors such as internal shading devices (draperies and blinds) and solar reflection or shading from adjacent buildings are not addressed [13]

Compared with thermal insulation standards usually used in cold climates, OTTV is more suitable for application to buildings in hot climates because it accounts for the solar heat gain at the building envelope [14]

The first country in Asia to develop an OTTV standard is Singapore. This standard was based on the ASHRAE Standards 90-75 and 90-80A, but with some refinements to suit local climate and construction practices. Other countries in South East Asia region, including Indonesia, Malaysia, Philippines, and Thailand, started implementing OTTV in 1980s and early 1990s. They used Singapore's development as a reference model to develop their building energy standards. At the same time, some countries in Central America, including Jamaica and Ivory Coast, also developed their building energy standards, using OTTV as a part of the requirements. Meanwhile the OTTV standard in Hong Kong was developed in 1991 [15].

However, there are some limitations in OTTV. The biggest limitation of the OTTV method is that it only deals with the building envelope and does not consider other aspects of building design such as lighting and air-conditioning. The use of OTTV as the only control parameter is inadequate and cannot ensure energy is used efficiently in the building [14]. This is because cooling load due to heat gain through envelope is usually only $10-20 \%$ of the total cooling load [16]. The OTTV method has also been criticized for limiting design freedom in architecture and restricting innovations. If alternative paths for code compliance are not provided, innovative designs that may exceed the OTTV limits but can achieve a higher overall efficiency will be excluded and discouraged. For example, designs employing daylighting to reduce energy consumption of electric lights will be restricted [15].

\section{Indonesian Standard on OTTV}

Standard for envelope energy conservation in Indonesia is described in Envelope Energy Conservation in Building Standards, SNI 6389:2011 [6]. Formulas used by the standard to calculate the OTTV is presented below.

The OTTV value for each wall with certain orientation is calculated using the following formula:

$$
\text { OTTV }=\alpha\left[\mathrm{U}_{\mathrm{w}} \mathrm{x}(1-\mathrm{WWR}) \times \mathrm{TD}_{\mathrm{ek}}\right]+(\mathrm{Uf} \times \mathrm{WWR} \times \Delta \mathrm{T})+
$$$$
\text { (SC x WWR x SF) }
$$

where:

OTTV = Overall thermal transfer value $\left(\mathrm{W} / \mathrm{m}^{2}\right)$ $\alpha \quad=$ Solar absorptance

$\mathrm{U}_{\mathrm{w}} \quad=$ Thermal transmittance of opaque wall $\left(\mathrm{W} / \mathrm{m}^{2} . \mathrm{K}\right)$

WWR $=$ Window-to-wall ratio

$\mathrm{TD}_{\mathrm{EK}} \quad=$ Equivalent temperature difference $(\mathrm{K})$

$\mathrm{SF} \quad=$ Solar factor $\left(\mathrm{W} / \mathrm{m}^{2}\right)$

SC $=$ Shading coefficient

$\mathrm{U}_{\mathrm{f}} \quad=$ Thermal transmittance of fenestration $\left(\mathrm{W} / \mathrm{m}^{2} . \mathrm{K}\right)$

$\Delta \mathrm{T}=$ Difference between internal and external temperature $(5 \mathrm{~K})$

The total OTTV of all walls is calculated using the following formula:

$\begin{aligned} \text { OTTV }= & \left(\mathrm{A}_{01} \times \mathrm{OTTV}_{1}\right)+\left(\mathrm{A}_{02} \times \mathrm{OTTV}_{2}\right)+\ldots+ \\ & \left(\mathrm{A}_{0 \mathrm{i}} \times \mathrm{OTTV}_{\mathrm{i}}\right)\end{aligned}$

where:

$\mathrm{A}_{\mathrm{oi}} \quad=$ Area of wall $\mathrm{i}\left(\mathrm{m}^{2}\right)$ including the area of fenestration

OTTV $_{\mathrm{i}}=$ OTTV of wall $\mathrm{i}\left(\mathrm{W} / \mathrm{m}^{2}\right)$ as a result of calculation using formula (1)

For the roof, the thermal transfer value is calculated using the following formula:

RTTV $=\alpha\left(\mathrm{A}_{\mathrm{r}} \times \mathrm{U}_{\mathrm{r}} \times \mathrm{TD}_{\mathrm{ek}}\right)+\left(\mathrm{A}_{\mathrm{s}} \times \mathrm{U}_{\mathrm{s}} \times \Delta \mathrm{T}\right)+\left(\mathrm{A}_{\mathrm{s}} \times \mathrm{SC} \times \mathrm{SF}\right)$

where:

RTTV = Overall thermal transfer value for roof $\left(\mathrm{W} / \mathrm{m}^{2}\right)$

$\alpha \quad=$ Solar absorptance

$\mathrm{Ar} \quad=$ Area of opaque roof $\left(\mathrm{m}^{2}\right)$

As $\quad=$ Area of skylight $\left(\mathrm{m}^{2}\right)$

Ao $=$ Total roof area $=\mathrm{Ar}+\mathrm{As}\left(\mathrm{m}^{2}\right)$

Ur $=$ Thermal transmittance of opaque roof $\left(\mathrm{W} / \mathrm{m}^{2} . \mathrm{K}\right)$

$\mathrm{TD}_{\mathrm{EK}} \quad=$ Equivalent temperature difference $(\mathrm{K})$

$\mathrm{SF} \quad=$ Solar factor $\left(\mathrm{W} / \mathrm{m}^{2}\right)$

$\mathrm{SC}=$ Shading coefficient

$\mathrm{U}_{\mathrm{s}} \quad=$ Thermal transmittance of fenestration (skylight) $\left(\mathrm{W} / \mathrm{m}^{2} . \mathrm{K}\right)$

$\Delta \mathrm{T}=$ Difference between internal and external temperature $(5 \mathrm{~K})$

The total OTTV is:

Total OTTV $=$ OTTV + RTTV

Based on the standard, the total OTTV should not exceed 35 $\mathrm{W} / \mathrm{m}^{2}$.

Note that equivalent temperature difference is defined by the weigh/area of the wall. The standard provides a table containing a conversion between the weight/area of the wall and the equivalent temperature difference.

Solar factor is calculated between 07.00 and 18.00. The standard provides a table containing solar factor for all orientation, i.e. N, NE, E, SE, S, SW, W, and NW.

Although window standards are now moving away from a previous standard referred to as Shading Coefficient (SC) to Solar Heat Gain Coefficient (SHGC), the Indonesian OTTV Standard still uses SC in its OTTV formula. One can perform 
an approximate conversion from SC to SHGC by multiplying SC with 0.87 .

And in this standard, the difference between internal and external temperature is set to $5 \mathrm{~K}$. There is no information on from where the value comes.

\section{OTTV Application}

An OTTV application based on Indonesian OTTV standard has been developed. The user interface can be seen in Figure 1. The application uses the following assumptions:

- Internal shading devices such as draperies are not included in the calculation.

- Shading from adjacent buildings is not included in the calculation either.

Roof does not have painting.

There is no skylight in the roof.

The interesting feature of the application is that after the users calculate the result, they have a chance to try Parametric Analysis. There are two kinds of parametric analysis: Single Parametric Analysis and Multi Parametric Analysis (Figure 2). Single parametric analysis is used to know the effect of each parameter on the OTTV value. There are seven parameters that are used in this analysis: wall absorptance, wall u-value, window-to-wall ratio, window u-value, shading coefficient, roof absorptance, and roof $u$-value. To know the effect of each parameter, the users can just slide the slider of each parameter to the right of to the left. Once they slide the slider, the percentage of parameter value change and the percentage of OTTV value change will appear. By doing the same for all parameters, the users can know which parameter affect the OTTV value most. This feature will be used in the experiment to know effect of each parameter on the OTTV value and will be presented in the next section.

Meanwhile, multi parametric analysis shows the effect of combined parameters value change to the OTTV value change. This parametric analysis uses the current value of each parameter to calculate the OTTV value. This feature can be used to find alternative value of each parameter in order to get the allowable OTTV value $\left(35 \mathrm{~W} / \mathrm{m}^{2}\right)$. This can be done by changing the value of each parameter until OTTV value of less than or equal to $35 \mathrm{~W} / \mathrm{m}^{2}$ is obtained. This feature will help the user to find alternative OTTV design with ease.

\section{Parametric Analysis on OTTV}

To know the effect of each parameter on OTTV value, a parametric analysis has been carried out. Seven parameters are used in this experiment: wall absoprtance, wall u-value, window-to-wall ratio, window u-value, shading coefficient, roof absorptance, and roof $u$-value.

In the experiment, each parameter value is increased to $40 \%$ bigger. The percentage of OTTV value change is recorded. The result is depicted in Figure 3. The figure shows that shading coefficient value change has the biggest impact to OTTV value. This is followed by window-to-wall ratio and wall u-value. And the parameter having the least impact on OTTV value is wall absorptance. There is no change in percentage of OTTV value even when this parameter is set to $40 \%$ bigger. Next, when we change the values of the parameters, the effect also changes (Figure 4). In this second experiment, we use bigger wall u-value, and smaller windowto-wall ratio, shading coefficient, and wall absorptance. From Figures 3 and 4, it can be seen that that there is an increase in percentage of OTTV value change as the wall u-value increase. In here, the increase of wall u-value by $19.9 \%$ causes $25 \%$ increase in the percentage of OTTV value change. Meanwhile, $12 \%$ decrease in window-to-wall ratio and $56,25 \%$ decrease in shading coefficient causes the percentage of OTTV value change decrease of 50\% and $33.33 \%$ respectively. Meanwhile there is still no change in percentage of OTTV value change even though the wall absorptance value is decreased. This result tells us that the parameter that has the biggest and the smallest impact on OTTV value is window-to-wall ratio and wall absorptance, respectively.

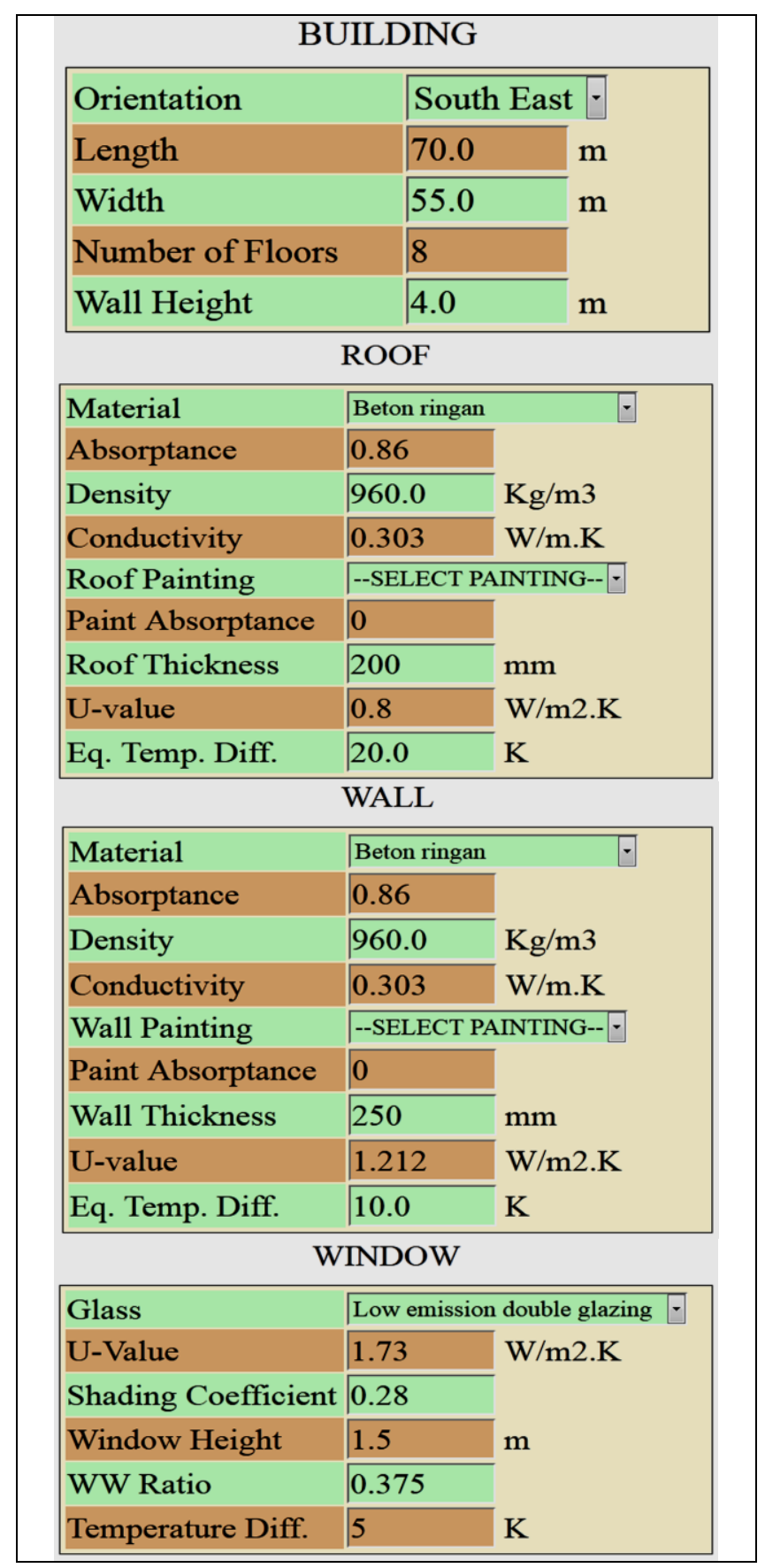

Fig. 1. The user interface of the OTTV application 


\begin{tabular}{|c|c|c|c|c|c|c|c|}
\hline \multicolumn{8}{|c|}{ SINGLE PARAMETRIC ANALYSIS } \\
\hline & & Initial Value & Current Value & $\%$ Change & Initial OTTV & Current OTTV & $\%$ Change \\
\hline Wall Absorptance & (1) & 0.86 & 1.032 & 21 & & 40.57 & 4 \\
\hline Wall U Value & 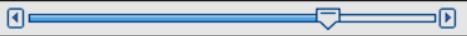 & 1.212 & 1.4544 & 20 & & 40.57 & 4 \\
\hline Window to Wall Ratio & (1) & 0.375 & 0.45 & 21 & & 42.28 & 8 \\
\hline Window U Value & $\sqrt{2}$ & 1.73 & 2.076 & 21 & 39.26 & 39.91 & 2 \\
\hline Shading Coefficient & (1) & 0.28 & 0.336 & 20 & & $\overline{42.41}$ & 9 \\
\hline Roof Absorptance & (1) 吃 & 0.86 & 1.032 & 21 & & 42.01 & 8 \\
\hline Roof U Value & 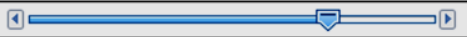 & 0.8 & 0.96 & 20 & & 42.01 & 8 \\
\hline \multicolumn{8}{|c|}{ MULTI PARAMETRIC ANALYSIS } \\
\hline & & Initial Value & Current Value & $\%$ Change & Initial OTTV & Current OTTV & \% Change \\
\hline Wall Absorptance & (1) & 0.86 & 0.688 & -20 & \multirow{7}{*}{39.26} & \multirow{7}{*}{33.41} & \multirow{7}{*}{-14} \\
\hline Wall U Value & =田 & 1.212 & 1.4544 & 20 & & & \\
\hline Window to Wall Ratio & (1) & 0.375 & 0.3 & -20 & & & \\
\hline Window U Value & 邽 & 1.73 & 2.076 & 21 & & & \\
\hline Shading Coefficient & (1) & 0.28 & 0.2239 & -20 & & & \\
\hline Roof Absorptance & (1) $\sqrt{2}$ & 0.86 & 0.688 & -20 & & & \\
\hline Roof U Value & $\nabla \rightleftharpoons$ & 0.8 & 0.96 & 20 & & & \\
\hline
\end{tabular}

Fig. 2. Single and Multi Parametric Analysis

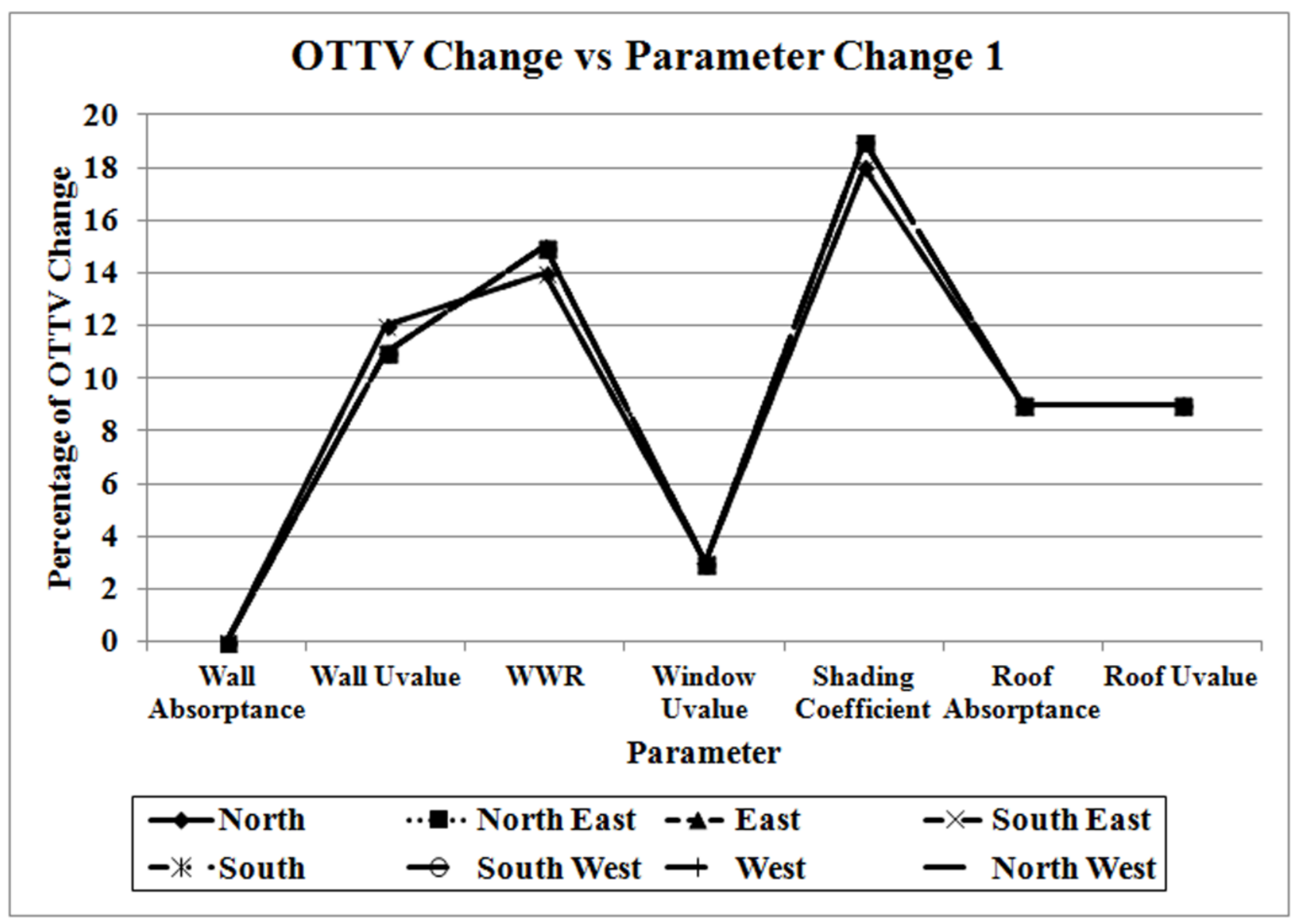

Fig. 3. Effect of parameter value change on OTTV value change 


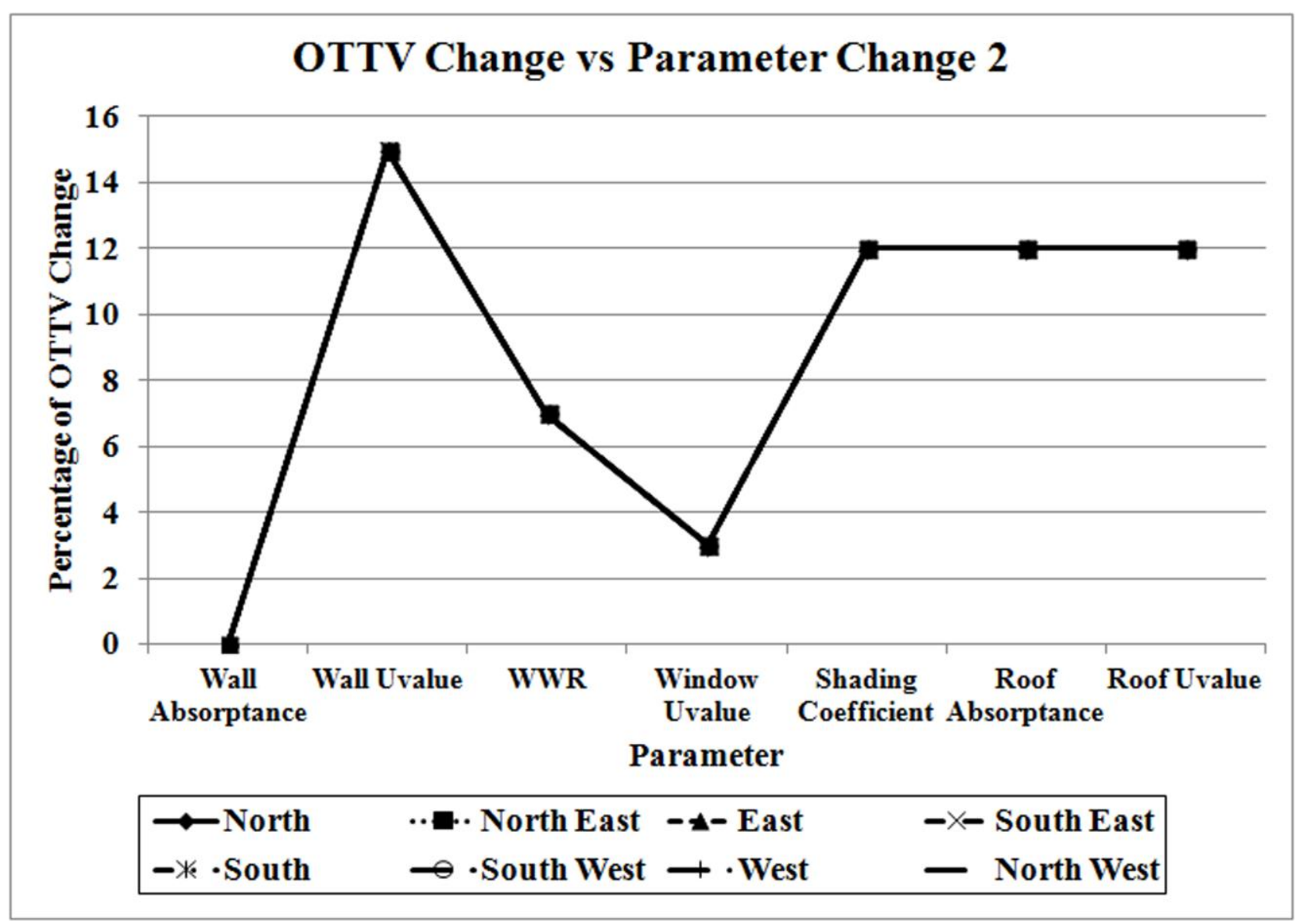

Fig. 4. Effect of parameter value change on OTTV value change

Both experiments above also use 8 different orientations: North, North East, East, South East, South, South West, West, and North West. As can be seen in Figure 3, at building orientation of North and South, the percentage of OTTV value change caused by wall u-value, window-to-wall ratio, and shading coefficient changes are little bit different than the other orientations. Meanwhile, as depicted in Figure 4, the percentage of OTTV value change is the same for all orientations.

\section{Discussion}

The experiment obtain a result that window-to-wall ratio is the most sensitive parameter in the OTTV formula. The $12 \%$ change is window-to-wall ratio causes $50 \%$ change in OTTV value. This fact states that architects must consider the size of the window when they design a building.

On the opposite, wall absorptance is the parameter having least effect on OTTV value. This result is obtained when the wall is painted. However, another experiment shows that a wall without painting gives higher OTTV value than the one with painting. Hence, painting the wall is a good practice for decreasing OTTV value, of course besides for aesthetic reason.

The experiment also reveals there is no effect from the orientation of the building on the percentage of OTTV value change. This may be because there is only small change in
OTTV value as a change in orientation. Based on an experiment using a set of data, the difference between the biggest (East and West orientations) and the smallest (North and South orientations) OTTV value is only $0.57 \mathrm{~W} / \mathrm{m}^{2}$.

\section{Conclusion}

- Knowing that window-to-wall ratio has the biggest impact in OTTV value, architects must consider very carefully the size of the window in the design.

- Another thing that needs to be considered is the use of painting in the wall. Wall painting is important not only for aesthethic reason, but also to reduce OTTV value. This is because the painting, especially the one with low absorptance, will help reduce the OTTV value.

- Different building orientations cause only small change in OTTV value.

\section{Acknowledgments}

Iman Paryudi would like to thank the Directorate General of Higher Education, Ministry of Education and Culture, Republic of Indonesia for the scholarship awarded to him. 


\section{References}

[1] Hong, W, Chiang, MS, Shapiro, RA, Clifford, ML: Building Energy Efficiency. The Asia Business Council, 2007.

[2] S. M. Wagner, P. C. N. Mellblom. The Next Generation of Energy Efficient Building Design: Where We Are and Should We be Going? http://best1.thebestconference.org/pdfs/016.pdf. Last accessed: February 22, 2012.

[3] Mechanical Engineering, University of Strathclyde. Case Study 2 - Low Energy Building Design Today. http://meserver.mecheng.strath.ac.uk/group2003/groupk/PDF/Case \%20studies2.pdf. Last accessed: December 4, 2011.

[4] A. M. Kazim. Assessments of primary energy consumption and its environmental consequences in the United Arab Emirates. Renewable and Sustainable Energy Reviews 2007:11:426-446.

[5] APEC. Peer Review on Energy Efficiency in Indonesia. Final Draft Report, 13 February 2012.

[6] Badan Standarisasi Nasional, Konservasi energy selubung bangunan pada bangunan gedung. SNI 6386:2011.

[7] R. Saidur, M. Hasanuzzaman, M.M. Hasan and H.H. Masjuki. Overall Thermal Transfer Value of Residential Buildings in Malaysia. Journal of Applied Sciences 2009:9:2130-2136, DOI: 10.3923/jas.2009.2130.2136

[8] American Society of Heating, Refrigerating and AirConditioning Engineers, ANSI/ASHRAE/IES Standard 90A-1980, Energy Conservation in New Building Design, Atlanta, 1980.
[9] J. Vijayalaxmi, Concept of Overall Thermal Transfer Value (OTTV) in Design Building Envelope to Achieve Energy Efficiency, Int. J. of Thermal \& Environmental Engineering, Vol. 1 No. 2, pp. 75 - 80, 2010.

[10] Faculty of Architecture, The University of Hong Kong Calculation and Application of OTTV (Overall Thermal Transfer Value) and U-Value, 2012.

[11] http://www.energyland.emsd.gov.hk/en/building/energy_us e/envelope.html, Building Envelope. Last accessed: July $10,2013$.

[12] S. Chiararattananon, J. Taveekun. An OTTV-based energy estimation model for commercial buildings in Thailand. Energy and Buildings 2004:36:680-689. DOI:10.1016/j.enbuild.2004.01.035

[13]http://www.bd.gov.hk/english/documents/code/OTTV02.pdf, General Principles of Control of Overall Thermal Transfer Value. Last accessed: June 26, 2013.

[14] F. W. H. Yik and K. T. Chan. Energy performance criteria for commercial buildings in Hong Kong: an alternative to OTTV, The Hong Kong Institution of Engineers Transactions 1995: 2 (1): 17-22

[15] Hui, SCM. Overall Thermal Transfer Value (OTTV): How to Improve Its Control in Hong Kong. Proceeding of the One-day Symposium on Building, Energy and Environment. Kowloon, Hong Kong, 1997.

[16] J. C. Lam, S. C. M. Hui, A. L. S. Chan. Overall Thermal Transfer Value Control of Building Envelope Design Part 2 - OTTV Parameters. Hong Kong Engineer 1993: 40-44. 